\title{
Persistence in punishment and extinction testing as a function of percentages of punishment and reward in training
}

\author{
CHARLES N. UHL \\ UNIVERSITY OF UTAH ${ }^{1}$
}

Rat Ss were trained in a Skinner-box fixed ratio analogue of the straight runway. A 3 by 2 by 2 factorial design incorporated $0 \%, 50 \%$, and $100 \%$ punished trials, $50 \%$ and $100 \%$ reinforcement with sucrose solution, and punishment vs. no punishment in extinction testing. Amount of responding in extinction testing increased with percentage of punishment and decreased with percentage of reinforcement.

The persistence of partially as compared to continuously reinforced behavior has been attributed by Amsel $(1958,1962)$ to conditioned mediating anticipatory frustration $\left(r_{F}\right)$ and its response-produced stimulation $\left(s_{F}\right)$. According to Amsel, the persistence of partially reinforced Ss is due to the discriminative control of $\mathrm{s}_{\mathbf{F}}$ over instrumental responding. This analysis invites extension to other forms of conditioned mediating response mechanisms whose response-produced stimulation may operate to maintain responding in extinction. In particular, instrumental responding brought under the control of stimuli produced by a conditioned anticipatory punishment response $\left(r_{p}-s_{p}\right)$ should increase resistance to extinction since $\mathrm{S}$ himself provides the discriminative $s_{p}$ for continued responding. Analyses of the functional similarity of frustration and punishment along these lines have been presented by Martin (1963) and by Wagner (1966).

Two studies (Brown \& Wagner, 1964; Logan, 1960) have demonstrated that punishment in training increases resistance to extinction. Both of these were runway studies with punishing electric shock in the goal box. Feirstein \& Miller's (1963) findings suggest that a center-gradual shock procedure, in which S's response speed controls the duration of shock, should be optimal for bringing the instrumental response under the control of $s_{\mathrm{p}}$. A Skinner-box analogue of the runway procedure was used, e.g., discrete FR "trials," with a centergradual punishment method. The effects on resistance to extinction of percentage of reinforcement, percentage of punishment, and punishment vs no punishment in extinction were tested in factorial combination.

Method

The Ss were 79 male albino rats $(150-200 \mathrm{~g})$ maintained at $80 \%$ of base weight on a $22-\mathrm{h}$ food deprivation schedule. Seven Ss were discarded because of failure to perform and $E$ error. Two Skinner boxes equipped with a retracting lever, a liquid dipper, white noise, a $25 \mathrm{~W}$ house light, and a grid floor, served as the apparatus. An ac shock source was connected to the grid floor through a scrambler and a $150 \mathrm{~K}$ ohm resistor in series with $\mathrm{S}$.

Each $S$ was pretrained to press the lever on FR 10 for a reinforcement of $3 \mathrm{sec}$ access to $.05 \mathrm{ml}$ of a $30 \%$ sucrose solution. A daily session consisted of 40 trials (FRs). The lever was retracted with the white noise and house light off for $18 \mathrm{sec}$ during the intertrial interval (ITI). Pretraining continued until s reached a criterion of mean daily time to complete a trial of not more than 4 sec.

Following pretraining, Ss were assigned to one of six groups based on the factorial combination of $50 \%$ and $100 \%$ reinforcement and $0 \%, 50 \%$, and $100 \%$ punishment. Gellerman orders determined $50 \%$ reinforcement and $50 \%$ punishment over trials. The reinforcement and punishment for the 50\%-50\% groups were programmed so that trials were equally divided among the four possible combinations of reinforcing and punishing events. A trial for all Ss began with the insertion of the lever and the onset of the light and white noise. After seven responses the light went off, and after 10 responses reinforcement was delivered if it was programmed and the ITI began. Punishment consisted of shock through the grid floor after the fifth response until after the seventh response. Shock intensity began at $20 \mathrm{~V}$ ac on the first punishment day, it was raised $5 \mathrm{~V}$ ac per day until $70 \mathrm{~V}$ ac was reached, and it remained at $70 \mathrm{~V}$ ac for two more days. All Ss received 13 days of training.

Each of the six training groups was split into a punishment-extinction group receiving shock on every testing trial and a nonpunishment-extinction group. Punishing shock intensity was $45 \mathrm{~V}$ ac on the first day of testing, and it was raised $10 \mathrm{~V}$ ac on each of the next two days of testing. No $S$ was punished on Days 4-6 of testing. Punishment was limited to $15 \mathrm{sec}$ if $\mathrm{S}$ failed to respond to turn it off. Otherwise the procedure for testing was exactly the same as for training except that no $S$ received reinforcement, and daily sessions were limited to 30 min on Days 1-3 of testing and 20 min on Days 4-6 of testing.

Resulfs

The effectiveness of punishment during training was reflected in reduced rate of responding. Mean daily time to complete the first five responses of a trial, averaged over blocks of two days beginning with the last three days of pretraining, was entered in a 2 by 3 by 8 analysis of variance incorportating percentage reinforcement( $P R)$, percentage punishment (PP), and blocks (B) of days. A 


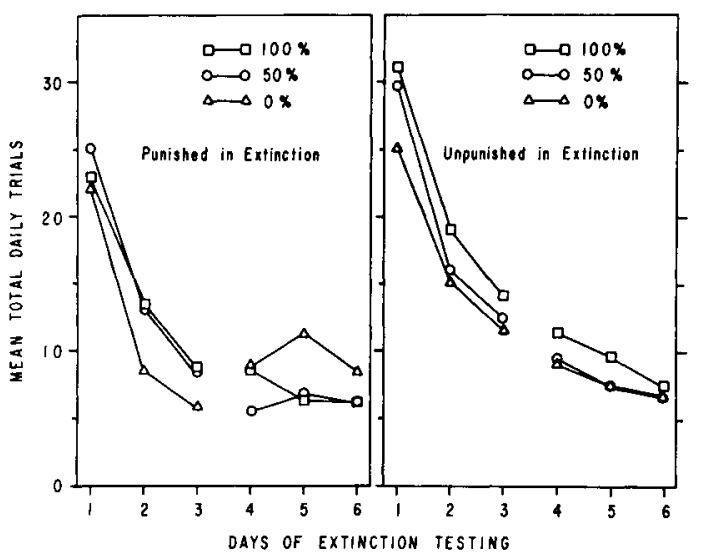

Fig. 1. Mean total daily trials completed in extinction testing as a function of days of testing with percentage of punishment in training as the parameter. Data for $\mathrm{Ss}$ punished in testing are given in the left panel and for Ss unpunished in testing in the right panel.

significant $P R$ effect $(F=35.62, d f=1 / 60, p<.001)$ revealed faster responding throughout training with $100 \%$ as compared to $50 \%$ reinforcement. A significantlinear component of the PP by $B$ interaction $(F=20.67, d f=$ $2 / 420, \mathrm{p}<.001$ ) reflected the divergence of response speed as training progressed with speed a negative function of PP. The respective means over the last six days of training for $0 \%, 50 \%$, and $100 \%$ punishment groups were $2.10,3.63$, and $4.01 \mathrm{sec}$, respectively.

Resistance to extinction, with or without punishment in extinction, was increased by punishment in training. Figure 1 represents mean total daily trials completed in extinction testing as a function of days of testing with PP as the parameter. The left panel of Fig. 1 shows the performance of Ss punished in extinction, and the right panel is for Ss unpunished in extinction. It can be seen in Fig. 1 that amount of extinction responding increased with PP. An analysis of variance on total daily trials completed incorporated PR, PP, punishment vs nonpunishment in extinction (PE), and repeated measures over the first three days (D) of extinction testing. Resistance to extinction was lower for $100 \%$ as compared to $50 \%$ reinforcement Ss $(F=84.56, d f=1 / 60, p<.001)$, and this effect increased as testing progressed as shown by the linear component of the PR by $D$ interaction $(F=30.35, d f=$ $1 / 120, p<.001)$. Total responding was reduced by punishment in extinction testing $(F=29.13, \mathrm{df}=1 / 60$, $p<.001)$. The increased resistance to extinction as a function of PP in training was shown in the linear component of the PP effect $(F=7.13, d f=1 / 60, p<.01)$. It is noteworthy that none of the interactions except PR by $D$ reached significance.

The same analysis of variance on the last three days of testing revealed only three significant sources of variance. Ss who had $50 \%$ reinforcement made more responses than Ss who had $100 \%$ reinforcement $(F=8.37$, $\mathrm{df}=1 / 60, \mathrm{p}<.01)$. Amount of responding declined from day to day $(F=9.76, d f=2 / 120, p<.001)$. There was a significant $D$ by $P E$ interaction $(F=3.77, d f=2 / 120$, $\mathrm{p}<.05)$ which reflects the less rapid decline in respond- ing on Days 4-6 of testing among Ss punished as compared to those not punished on Days 1-3 of testing. This finding suggests that punishment in extinction produced only temporary suppression of responding. For Ss not punished in training and punished on Days 1-3 of testing, the absence of punishment on testing Days 4-6 may have acted as a reinstatement of the stimulus complex controlling responding in training.

\section{Discussion}

These findings support the expectation that punishment and frustrative nonreward produce functionally similar effects on resistance to extinction, and they confirm and extend similar results reported by Brown \& Wagner (1964) and by Logan (1960). A noteworthy feature of the results was the absence of interaction between the experimental variables indicating additivity of their effects. This too confirms Brown \& Wagner (1964) who found that punished Ss were more resistant to the effects of nonreinforcement, and partially reinforced Ss were more resistant to the effects of punishment.

Although the increased resistance to extinction of a punished response when the reaction to punishment is compatible with instrumental responding now seems well established, the details of the mechanism(s) underlying the effects are by no means clear. Conditioning of the instrumental response to the discriminative control of $s_{p}$ is an attractive hypothesis which helps to integrate punishment effects with frustrative nonreward effects. However, in addition to $s_{\mathrm{p}}$ discriminative control, there are other features of the present experimental procedure which may have contributed to resistance to extinction. Extinction responding resulted in the offset of the stimulus (light on) associated with punishment, thus potentially providing for conditioned reinforcement by fear reduction. Also, extinction responding resulted in the production of stimuli (light and white noise off and lever retracted) signalling "safety" from shock. Separation of discriminative, motivating, and reinforcing properties of stimuli associated with punishment must await further research.

\section{References}

Amsel, A. The role of frustrative nonreward in noncontinuous reward situations. Psychol. Bull., 1958, 55, 102-119.

Amsel, A. Frustrative nonreward in partial reinforcement and discrimination learning: Some recent history and a theoretical extension. Psychol. Rev., 1962, 69, 306-328.

Brown, R. T., \& Wagner, A. R. Resistance to punishment and and extinction following training with shock or non-reinforcement. J. exp. Psychol., 1964, 68, 503-507.

Feirstein, A. R., \& Miller, N. E. Learning to resist pain and fear: Effects of electric shock before versus after reaching goal. $J$. comp. physiol. Psychol., 1963, 56, 797-800.

Logan, F. A. Incentive. New Haven: Yale University Press, 1960.

Martin, B. Reward and punishment associated with the same goal response: A factor in the learning of motives. Psychol. Bull., $1963,60,441-451$.

Wagner, A. R. Frustration and punishment. In R. N. Haber (Ed.), Current research in motivation. New York: Holt, Rinehart, \& Winston, 1966. Pp. 229-239.

\section{Note}

1. These data were collected while the author was a visiting instructor at the University of Colorado 1965-66. 